\title{
Modelos de crescimento sob restrições externas: uma abordagem empírica à La Thirlwall para o Brasil pré-crise*
}

Johana Martinez Lezcano'
Rodrigo Vilela Rodrigues

\begin{abstract}
Resumo: Com base nas relações brasileiras atuais com o setor externo, e na relevância dessas relações para sua economia, o presente trabalho testou a hipótese de que o Brasil, mesmo antes da crise de 2008, ainda tinha seu desenvolvimento restrito por relações internacionais. Tal hipótese foi testada com base na Lei de Thirlwall, que verifica se o crescimento econômico é restrito por questões de balanço de pagamentos. A metodologia de séries temporais e testes de diferenças de médias demonstraram que, em uma série de especificações, o Brasil pré-crise de 2008 ainda tinha seu crescimento restrito pelas relações externas.
\end{abstract}

Palavras-chave: Lei de Thirlwall, crescimento econômico, Brasil.

\section{Classificação JEL: O19}

Models of growth under external restrictions: empirical approach à la thirwall for pre-crisis brazil

\begin{abstract}
Based on current Brazilian relations with the external sector, and the importance of these relationships for its economy, the present study tested the hypothesis that Brazil even before the 2008 crisis, still had her restricted development in international relations. This hypothesis was tested based on Thirlwall's Law, which verifies that the economic growth is constrained by balance of payments issues. The methodology of time series and mean comparison tests showed that in a number of specifications, the 2008 pre-crisis Brazil still had its restricted growth for external relations.
\end{abstract} Keywords: Thirlwall Law, economic growth, Brazil.

1 Mestre em Economia Aplicada pela UFSCar/Sorocaba e cursando MBA em Gestão financeira, Controladoria e Auditoria (FGV - Curitiba). Trabalha na Usina Hidrelétrica Itaipu. E-mail: johanam@itaipu.gov.py.

2 Doutorado em Economia Aplicada pela Universidade Federal de Viçosa. Professor Associado da Universidade Federal de São Carlos. E-mail: rvilela@ufscar.br. 


\section{Introdução}

No decorrer das últimas décadas a temática referente ao crescimento econômico tem conquistado um espaço relevante nas discussões realizadas não somente no âmbito acadêmico, mas também na esfera política e social. A maior parte das teorias voltadas a essa questão pretende explicar o que determina a taxa de crescimento do produto e qual o motivo que justifica o diferencial nas taxas de crescimento das nações (McCOMBIE; THIRLWALL, 1994).

O debate existente em torno dessas diversas teorias de crescimento aparece como um importante pilar para tentar explicar a experiência econômica das distintas nações ao redor do mundo. Sendo assim, estudos desta índole devem ser levados em consideração pelos países desenvolvidos ou em desenvolvimento, devido ao seu papel preponderante nas análises sobre o desempenho econômico das nações (VIEIRA; VERÍSSIMO, 2009).

A acentuada fragilidade estrutural predominante nas economias em desenvolvimento exacerba a necessidade de tentar desvendar quais as restrições impostas ao crescimento econômico desses países. Nesse sentido, um fenômeno comum que tem caracterizado a conjuntura econômica da América Latina, nas últimas décadas, refere-se à presença de profundos desequilíbrios estruturais. $\mathrm{O}$ endividamento externo, a volatilidade financeira e a deterioração dos termos de troca aparecem como inibidores do crescimento destas nações (REZENDE, 1993 apud MAIA; NUNES, 2006).

Seguindo essa linha de raciocínio, o Brasil passou a década de 90 com resultados pouco satisfatórios em termos de crescimento econômico, mesmo que a situação externa não mais fosse aquela dos desequilíbrios citados dos anos $80 . \mathrm{Na}$ primeira década do século XXI, apoiada em um forte crescimento de suas exportações, em especial commodities para a China, o país cresceu consideravelmente, corroborando a dependência de boas relações externas e crescimento mundial.

De alguns anos para cá, no entanto, a situação volta a se deteriorar, e, no ano de 2013, o déficit em conta corrente alcançou a casa dos 4,5\% do PIB, com pouca perspectiva de melhora. Os investimentos externos, de acordo com estimativas do Banco Central, podem recuar $17 \%$, reduzindo a margem credora do país na dívida pública de US\$ 93 bilhões em 2013 para US\$ 49,1 bilhões. A desvalorização cambial pode exercer papel de reequilíbrio na conta comercial, mas os maiores juros do mundo ainda tem o impacto mais poderoso (VALOR ECONÔMICO, 2015).

Os fatos que estilizaram a economia brasileira, nos últimos decênios, aliados à atual deterioração do balanço de pagamentos propiciam vincular seu crescimento econômico às teorias estruturalistas, inauguradas por Thirlwall (1979), onde o produto potencial da economia encontra-se condicionado às restrições externas enfrentadas pelo país.

Desse modo, o presente trabalho tem por objetivo testar a hipótese de que o Brasil, mesmo antes da crise de 2008, ainda tinha seu desenvolvimento restrito 
por desequilíbrios no balanço de pagamentos. Com citado intuito, o presente estudo divide-se nessa introdução, seguida de uma revisão de literatura teórica e empírica sobre crescimento econômico com restrição externa, as fontes de informações utilizadas, a metodologia empregada, os resultados e suas discussões, além das conclusões.

\section{Revisão de literatura}

\subsection{O Modelo Original: Thirlwall (1979)}

Em sua formulação original, Thirlwall (1979) modela, de forma sucinta, o que representaria a restrição externa de crescimento de um país, expressando da seguinte maneira a sua condição de equilíbrio do Balanço de Pagamentos em conta corrente:

$$
P d_{t} X_{t}=P f_{t} M_{t} E_{t}
$$

em que $\boldsymbol{X}_{\boldsymbol{t}}$ representa a quantidade de exportações; $\boldsymbol{P} \boldsymbol{d}_{t}$ é o preço das exportações em moeda doméstica; $\boldsymbol{M}_{\boldsymbol{t}}$ se constitui no volume de importações; $\boldsymbol{P} \boldsymbol{f}_{\boldsymbol{t}}$ é o preço das importações, medido em moeda estrangeira; $\boldsymbol{E}_{\boldsymbol{t}}$ representa a taxa de câmbio nominal; e $t$ é o índice de tempo. Nessa especificação inicial, portanto, o equilíbrio externo considera apenas a balança comercial.

Após transformar as variáveis em nível (acima) em taxas de crescimento, separar definições específicas de demanda por exportações e importações, chega-se a uma taxa de crescimento do produto condizente com o equilíbrio do balanço de pagamentos, sem e com termos de troca, simbolizando, no primeiro caso, a possibilidade da variação dos termos de troca ser insignificante no longo prazo, que pode ser consultada em Thirlwall (1979):

$$
\begin{gathered}
y_{b t}=\frac{x_{t}}{\pi}(2) \\
y_{b t}=\frac{x_{t}+(1+\varphi)\left(p_{d}-e-p_{f}\right)}{\pi}
\end{gathered}
$$

As equações acima representam a denominada Lei de Thirlwall (LT) nas suas formulações originais. De acordo com a LT, a taxa de crescimento de longo prazo condizente com o equilíbrio do Balanço de Pagamentos $\left(Y_{b t}\right)$ resulta da razão entre a taxa de crescimento das exportações $\left(\boldsymbol{x}_{\boldsymbol{t}}\right)$ e a elasticidade-renda das importações $(\boldsymbol{\pi})$, na equação (2). A equação (3), por sua vez, representa o caso em que os termos de troca também são considerados em Conta Corrente Equilibrada (CARVALHO, 2005, p. 137), sendo $\phi=$ elasticidade-preço da demanda por importações; $p_{d}=$ taxa de crescimento dos 
preços das exportações em moeda doméstica e $p_{f}=$ taxa de crescimento dos preços das importações em moeda estrangeira; $e=$ taxa crescimento do câmbio.

Ao avaliar, empiricamente, a validade da Lei de Thirlwall para os países desenvolvidos, Thirlwall (1979) constatou a existência de uma grande aproximação entre as taxas de crescimento dessas nações e aquela prevista pelo modelo teórico. Entretanto, o mesmo não acontecia ao analisar a trajetória de crescimento dos países em desenvolvimento. Nesse caso, o poder explicativo do modelo tornava-se menor, sobretudo, por desconsiderar, entre outras questões, a possibilidade de financiamento de déficits comerciais por meio do influxo de capitais, a influência das variações no câmbio real, a dinâmica do endividamento externo, etc.

\subsection{Incorporando o fluxo de capitais: versão Thirlwall e Hussain (1982)}

Com o propósito de aprimorar a "regra simples”, Thirlwall e Hussain (1982) realizam a primeira tentativa de incorporar os fluxos de capitais nas análises de crescimento com restrição externa, posto que no modelo original, o Balanço de Pagamentos refletia apenas o resultado da balança comercial. Este avanço na modelagem foi relevante visto que após o período de desregulamentação dos fluxos de capitais internacionais, iniciada na década de 1980, estes passaram a ganhar considerável espaço relativamente às transações de mercadorias, impulsionando a elevação da volatilidade cambial e das taxas de juros (CARVALHO et. al., 2008).

Assim, Thirlwall e Hussain (1982) iniciaram a sua análise partindo da seguinte especificação, a qual introduziram a conta capital, ou seja, a possibilidade de um desequilíbrio inicial na balança comercial:

$$
P d_{t} X_{t}+F_{t}=P f_{t} M_{t} E_{t}
$$

em que $\boldsymbol{F}_{\boldsymbol{t}}$ é o valor nominal do fluxo de capital medido em moeda doméstica, sendo F $>0$ (entrada) ou F $<0$ (saída) de capitais; $\boldsymbol{X}_{\boldsymbol{t}}$ representa a quantidade de exportações; $\boldsymbol{P} \boldsymbol{d}_{\boldsymbol{t}}$ é o preço das exportações em moeda doméstica; $\boldsymbol{M}_{\boldsymbol{t}}$ se constitui no volume de importações; $\boldsymbol{P} \boldsymbol{f}_{\boldsymbol{t}}$ é o preço das importações, medido em moeda estrangeira; $\boldsymbol{E}_{\boldsymbol{t}}$ representa a taxa de câmbio nominal (preço doméstico da moeda estrangeira); e $t$ é o índice de tempo. As equações (2) e (3), sob a nova configuração, apresentam-se da forma que segue:

$$
y^{*} b t=\frac{(1-\theta)\left(f-p_{d t}\right)+\theta x_{t}}{\pi}
$$

Em que $\theta$ e (1- $\theta)$ representam, respectivamente, a participação das exportações e dos fluxos de capitais no total das receitas do setor externo, ou seja, qual a parcela das importações é paga pelas exportações e qual á paga pela entrada de capitais. 
De acordo com a equação (5), um aumento na elasticidade-renda das importações pode ser contornado com um maior fluxo de capitais para o país (estratégia debt-led growth). Em outras palavras, um determinado país poderia incorrer em déficits comerciais, desde que pudesse financiá-los com a entrada de capitais externos, o que permitiria ao país em questão sustentar uma taxa de crescimento elevada. A fuga de capitais, por sua vez, agiria no sentido oposto, deprimindo a taxa de crescimento, podendo até torná-la negativa.

Contudo, mesmo considerando esta versão ampliada da LT, Thirlwall e Hussain (1982) constataram, empiricamente, que a contribuição dos fluxos de capitais na explicação da trajetória de crescimento, para a maioria das nações da sua amostra, não se mostrou significativa, ou seja, embora a possibilidade de movimentos de capitais proporcionasse uma espécie de alívio à restrição externa, decorrente do comércio (modelo original), estes não conseguem acabar com a restrição imposta pelo Balanço de Pagamentos.

\subsection{Incorporando o endividamento externo e o serviço da dívida: ex- tensões do modelo com fluxos de capitais}

Outra restrição do modelo diz respeito ao endividamento externo acumulado, o qual não recebe um tratamento apropriado na especificação anterior. Nesse sentido, a conjuntura da economia mundial nos anos oitenta, com as profundas crises de endividamento externo contaminando a maior parte dos países em desenvolvimento, e com a participação cada vez mais significativa das despesas com serviços da divida na conta corrente, introduziu a preocupação de incorporar a dinâmica do endividamento nas análises de crescimento com restrição externa (CARVALHO et. al., 2008).

Dentre as contribuições concedidas à modelagem desde Thirlwall e Hussain (1982), cabe mencionar o trabalho realizado por McCombie (1997), que considerou não apenas o papel dos fluxos de capitais sobre a trajetória de crescimento das nações, mas também os efeitos da dívida externa. Dessa forma, o modelo desenvolvido pelos autores derivou uma taxa de crescimento de longo prazo condizente com uma restrição de endividamento sustentável. Seguindo a mesma linha, Moreno-Brid (1998-1999) apresentou um modelo que passou a considerar a possibilidade tanto de um desequilíbrio inicial da balança comercial, como de um endividamento estável. Assim, adotando um procedimento um pouco diverso, a taxa de crescimento resultante mostrou-se análoga àquela encontrada por McCombie (1997).

Outra tentativa de avançar nessa área de pesquisa foi realizada por Elliot e Rhodd (1999), que, além de incluir a condição de endividamento estável, passaram a incorporar o endividamento externo acumulado, isto é, a dinâmica da dívida e seu serviço. Dando seguimento à análise aqui reportada, sobre os modelos ampliados da LT com fluxo de capitais, posteriormente, Moreno-Brid (2003) passou a incorporar também, explicitamente, o pagamento de juros da dívida no equilíbrio externo de longo prazo, que tinha sido desconsiderado na versão apresentada em 1998. 
Sustentando a mesma condição de endividamento estável, baseada na constância da relação conta corrente/PIB, a modelagem desenvolvida em 2003 aprimorou os trabalhos precedentes, uma vez que os resultados encontrados sugerem que a inclusão explícita do serviço da dívida pode, de fato, modificar, consideravelmente, o equilíbrio externo de longo prazo.

Deste modo, adaptando a versão apresentada por Thirlwall e Hussain (1982) para incluir formalmente o pagamento de juros, o modelo restrito pelo BP derivado por Moreno-Brid (2003) pode ser resumido pelas seguintes equações, em termos de taxas de crescimento:

$$
\begin{gathered}
p_{f}+\boldsymbol{m}=\theta_{1}\left(p_{d}+x\right)-\theta_{2}\left(p_{d}+r\right)+\left(1-\theta_{1}+\theta_{2}\right)\left(p_{d}+f\right) \\
\theta_{1}=p_{d} x / p_{f} m \\
\theta_{2}=p_{d} r / p_{f} m
\end{gathered}
$$

A equação (6) corresponde à especificação dinâmica da nova condição de equilíbrio no $\mathrm{BP}^{3}, m=$ taxa de crescimento das importações; $r=$ pagamento líquido de juros ao exterior, medido em termos reais; e $f=$ representa o influxo líquido de capitais externos.

Por sua vez, a equação (7) indica a parcela das despesas com importações cobertas pela renda decorrente das exportações $\left(\boldsymbol{\theta}_{1}>0\right)$, enquanto a equação (8) mostra a proporção do pagamento líquido de juros ao exterior relativamente às importações $\left(\boldsymbol{\theta}_{2}>0\right)^{4}$, sendo ambos mensurados no período inicial. Como $\boldsymbol{\theta}_{1}$ e $\boldsymbol{\theta}_{2}$ são valores positivos, portanto, o termo $\left(1-\theta_{1}+\theta_{2}\right)$ representa a razão entre o fluxo de capitais externos e as importações.

Para garantir que a acumulação da dívida externa seja não explosiva, conforme proposto por Moreno-Brid (1998-1999; 2001), é imposta a condição de endividamento sustentável, fundamentada na manutenção da razão entre o déficit em conta corrente $(F)$ e o PIB $(Y)^{5}$ :

$$
F / Y=k(9)
$$

3 Por simplificação, nessa versão estendida, a taxa nominal de câmbio ( $e$ ) é mantida fixa e igual a um, motivo pelo qual esta variável não aparece na equação (6).

${ }^{4} \mathrm{O}$ fato do $\boldsymbol{\theta}_{2}>0$, ou o sinal negativo do segundo termo do lado direito da equação (6), sugere que o país em questão é um devedor líquido (MORENO-BRID, 2003).

5 A constância da relação déficit em conta corrente/PIB, dada por $F / Y$, representa a restrição imposta à entrada de capitais externos, que é endogenamente determinada. De modo que, nesse caso, o $F$ representa o montante de déficit em conta corrente que um dado país pode suprir por meio do influxo de capitais, respeitando a condição de endividamento sustentável (MORENOBRID, 2003). 
em que $k$ é uma constante. Por definição, tem-se que $F=p_{d}+f$ eY $=$ $\boldsymbol{p}_{\boldsymbol{d}}+\boldsymbol{y}$, de modo que, em termos de taxa de variação, a equação (9) pode ser reescrita como:

$$
p_{d}+f=p_{d}+y
$$

Substituindo a condição acima imposta na equação (6), resolve-se para a taxa de crescimento condizente com o equilíbrio externo, a qual, além de incorporar o pagamento líquido de juros ao exterior, ainda avaliza uma trajetória de longo prazo sustentável para a dívida externa acumulada, assumindo variação insignificante dos termos de troca no longo prazo:

$$
y^{*} b=\frac{\theta_{1} x-\theta_{2} r}{\pi-\left(1-\theta_{1}+\theta_{2}\right)}
$$

Desta forma, Moreno-Brid (2003) aplicou a análise acima detalhada para o caso mexicano, entre 1967 e 1999, derivando as taxas de crescimento compatíveis com o equilíbrio externo como especificadas pelas equações acima.

Finalmente, procurando incorporar os diferentes elementos que compõem o equilíbrio de longo prazo do BP, a próxima análise abordará, ainda, a formulação apresentada por Carvalho e Lima (2007-2009). Assim, visando identificar a função desempenhada pelos diversos componentes do equilíbrio externo, os autores apresentam uma especificação do BP que inclui o comércio, os termos de troca, o fluxo de capitais (desconsiderando qualquer restrição à sua entrada) e o pagamento de serviços do capital, que abarca não somente os gastos com juros, mas toda a conta de serviços, resultando na seguinte equação de equilíbrio para o produto:

$$
y^{*_{*} b}=\frac{\theta_{1} x+(1+\varphi)\left(p_{d}|e| p_{f}\right)-\theta_{2} r+\left(1-\theta_{1}+\theta_{2}\right) f}{\pi}
$$

De forma equivalente aos casos anteriores, se for considerada a hipótese de que os preços relativos, medidos em moeda comum, são negligenciáveis no longo prazo, isto é, sem incluir os termos de troca, a equação (12) pode ser simplificada para:

$$
y^{*_{*}}=\frac{\theta_{1} x-\theta_{2} r+\left(1-\theta_{1}+\theta_{2}\right) f}{\pi}
$$

De acordo com as principais conclusões encontradas por Carvalho e Lima (2007-2009), a trajetória de crescimento da economia brasileira, entre 1930 e 2004, foi consistente com a abordagem de crescimento sob restrição externa à la Thirlwall. Por 
sua vez, o componente comercial, dado pela razão das elasticidades-renda, foi responsável pela maior parte desse crescimento, seguido pelos termos de troca, que também contribuíram positivamente. Já o pagamento de serviços do capital apresentou um valor negativo, intensificando, portanto, a restrição decorrente do BP, enquanto que o fluxo de capitais não teve nenhuma participação no aumento dessa restrição.

A partir dos modelos descritos nesta seção, percebe-se que desde a primeira tentativa feita por Thirlwall e Hussain (1982), de incorporar o fluxo de capitais à LT original, vários outros autores passaram a apresentar extensões deste modelo. Assim, visando melhor elucidar a trajetória de crescimento das economias em desenvolvimento, estas versões ampliadas procuraram incorporar não apenas a conta capital, mas também outros componentes do Balanço de Pagamentos - tais como o pagamento dos serviços do capital, as receitas e despesas dos serviços dos fatores de produção, além de incluir as condições para a manutenção de um endividamento sustentável.

\subsection{Evidências empíricas para países em desenvolvimento}

Existe uma variedade de trabalhos validando empiricamente a abordagem do crescimento sob restrição externa na tradição de Thirlwall. Dentre os estudos destinados aos países em desenvolvimento, incluindo em sua amostra as nações membros do MERCOSUL (individualmente ou na sua totalidade), têm-se os trabalhos de Thirlwall e Hussain (1982); López e Cruz (2000); Bértola et. al. (2002); Holland et. al. (2004); Nakabashi e Porcile (2004); Maia e Nunes (2006); Nakabashi (2007); Carvalho e Lima (2008); Soares (2010); Esteves e Correia (2010); etc.

A seguir serão detalhadas algumas dessas contribuições já realizadas no campo da abordagem de crescimento restrito pelo Balanço de Pagamentos. Tendo em vista a vasta literatura empírica existente, serão discutidos somente os trabalhos que apresentem características comuns ao presente estudo.

Nesse campo, um dos estudos pioneiros destinado a países em desenvolvimento, incluindo, dos membros do MERCOSUL, o Brasil, diz respeito ao artigo de Thirlwall e Hussain (1982). Estendendo o modelo original de Thirlwall (1979), os autores passaram a incorporar a possibilidade de influxos de capitais externos na condição de equilíbrio inicial. A análise foi aplicada para uma amostra de 20 países em desenvolvimento, sob a hipótese de que a conta de capitais, de fato, exerceria um papel relevante sobre a trajetória de crescimento dessas nações. Os procedimentos metodológicos são semelhantes aos utilizados nesse estudo, tendo como bases elasticidades-renda das importações já consagradas na literatura combinadas a estimativas próprias.

Assim, para diversos períodos de tempo, Thirlwall e Hussain (1982) computaram o desvio médio entre a taxa de crescimento efetiva e a taxa de crescimento prevista pelos modelos teóricos (original e com fluxo de capitais). De acordo com os resultados obtidos, parte da divergência observada entre a taxa de crescimento 
real e a taxa de crescimento decorrente do cálculo da LT, podia ser explicada pela presença de capitais externos.

Mais especificamente, para os países em que a taxa efetiva de crescimento se mostrou superior à prevista pela LT, a entrada de capitais ilustrava $2 \%$ dessa diferença, enquanto que, para os países que apresentaram uma taxa real inferior à derivada pela LT, o fluxo de capitais foi responsável por -0,8\% (THIRWALL; HUSSAIN, 1982).

Por sua vez, ao comparar a taxa de crescimento observada com aquela prevista pelo modelo ampliado, Thirlwall e Hussain (1982) constataram que -0,7\% dessa diferença decorreram de variações dos termos de troca, no caso dos países que apresentaram uma taxa real superior à prevista pela LT, e -1,6\% para as nações em que a taxa de crescimento efetiva se mostrou inferior que a taxa dada pela LT.

Posteriormente, López e Cruz (2000) testaram, empiricamente, a validade da Lei de Thirlwall para Argentina, Brasil, Colômbia e México. Assim, para o período entre 1865 e 1996, os autores buscaram investigar a relação de longo prazo existente entre as séries produto e exportações, por meio das técnicas de cointegração proposta por Johansen, o que do ponto de vista deles bastaria para verificar a validade da LT. Além disso, implementaram um teste de causalidade de Granger para ambas as séries.

Em concordância com os resultados encontrados, Lopez e Cruz (2000) corroboraram para os quatro países da amostra, a validade da Lei de Thirlwall, durante o período em questão, uma vez que foi confirmada a existência de uma relação de longo prazo entre o produto e as exportações. Adicionalmente, verificaram que, à exceção do caso mexicano, há evidências favoráveis para a relação de causalidade sustentada pela LT, com as exportações causando o produto, de modo que, aumentos nas exportações tendem a melhorar a trajetória de crescimento das nações.

Em seguida, Holland et. al. (2004) realizaram uma aplicação empírica, visando testar a validade da Lei de Thirlwall para dez economias da América Latina (incluindo Argentina, Bolívia, Brasil, Chile, Colômbia, Equador, México, Peru, Uruguai e Venezuela). Para o período compreendido entre 1950 e 2000, os autores estimaram as elasticidades-renda das importações para os países da amostra, empregando o instrumental econométrico de séries temporais. Logo, essas elasticidades foram substituídas na equação da LT original, obtendo-se a taxa de crescimento condizente com o equilíbrio externo.

Por fim, é feita uma comparação entre a taxa de crescimento prevista pelo modelo teórico e a taxa de crescimento efetiva. Segundo os resultados, a taxa de crescimento compatível com o equilíbrio do Balanço de Pagamentos se mostrou muito próxima à taxa de crescimento real, no caso da Argentina, Chile, Peru e Uruguai. Já para as economias remanescentes, observaram-se certa diferença (entre 1\% e 1,5\%) entre ambas as taxas (HOLLAND et. al., 2004).

Portanto, levando em conta os resultados encontrados, Holland et. al. (2004), concluem que a restrição decorrente do Balanço de Pagamentos, de fato, é importante para explicar a trajetória de crescimento das nações Latino-americanas, de 
modo que há evidências a favor da validade da Lei de Thirlwall para essa amostra de países, ao longo do período em questão.

Carvalho e Lima (2008) apresentaram uma análise empírica, para um vasto conjunto de países, empregando uma metodologia alternativa para as estimações. Por meio do instrumental de dados em painel com efeito específico, os autores estimaram as elasticidades-renda da demanda por importações, com base na equação de equilíbrio do modelo estendido, que considera, além dos termos de troca, a influxo de capitais externos.

Em concordância com o experimento empírico reportado, empregando dados anuais entre 1980 e 2004, constatou-se a existência de uma correlação inversa entre as elasticidades-renda da demanda por importações e a taxa de crescimento do PIB. Isso, por sua vez, corroborou a validade da Lei de Thirlwall, para uma extensa amostra. Portanto, para uma cross-section de países, os autores confirmaram a legitimidade da restrição decorrente do Balanço de Pagamentos como fator inibidor do crescimento do produto dessas economias (CARVALHO; LIMA, 2008b).

Esteves e Correia (2010) publicaram uma aplicação da Lei de Thirlwall para uma amostra composta por cinco nações sul-americanas, ao longo do período compreendido entre 1980 e 2005 . O objetivo do artigo consistia em demonstrar que, para tal período, as elasticidades-renda das importações, dos países em questão, se modificaram de maneira a atenuar a restrição imposta pelo equilíbrio do Balanço de Pagamentos, sobre a trajetória de crescimento destas economias.

Em outras palavras, parte-se da hipótese de que uma queda na entrada de capitais externos tenderia a diminuir a elasticidade-renda da demanda por importações, o que resultaria em um aumento da taxa de crescimento do produto relativamente ao caso em que essa elasticidade-renda permanecesse invariante durante o afluxo de capitais. Assim, empregando a metodologia Engle-Granger, os autores iniciaram a análise com base na condição de equilíbrio externo do modelo estendido desenvolvido por Thirlwall e Hussain (1982).

De acordo com os resultados apurados por Esteves e Correia (2010, p. 12), "Para os países Latino-americanos aqui estudados, a lei de Thirlwall parece ser uma boa representação para a trajetória de crescimento destes, sendo esta determinada fundamentalmente, pelas exportações e pela elasticidade renda das importações". Para finalizar, eles assinalaram "... que quanto maior for a importância relativa da conta corrente em relação às exportações, maior deve ser a intensidade de variação sobre a elasticidade renda das importações, de maneira a suavizar a restrição que é imposta ao crescimento pela lei de Thirlwall no curto prazo" (ibid, p. 12).

Todos os estudos acima relacionados incluíam o Brasil em sua amostra, Bértola, Higachi e Porcile (2002) testaram a Lei original de Thirlwall para o Brasil, entre 1890 e 1973, perfazendo, dessa forma, todo período que se compreende desde a etapa exported-led ao final do século XIX até o período em que o capital passa a ser extremamente relevante na definição da restrição externa. Por meio de cointegração, conseguem corroborar a hipótese de que a LT se aplica a economia brasileira no período estudado. 
Jayme Jr (2007), assim como López e Cruz (2000) utilizaram análises de cointegração e causalidade para corroborar a LT para o Brasil entre 1955 e 1998.

Britto e McCombie (2009) testaram a validade da lei de Thirlwall comparando as elasticidades tanto no modelo original quanto no estendido (proposto por Moreno-Brid (2003)). Mesmo com metodologia diversa das anteriores e do presente trabalho, corrobora-se a hipótese de que o crescimento brasileiro é restrito pelo balanço de pagamentos, seja pelo fluxo comercial, de capitais ou endividamento.

Com trabalhos que incluem o Brasil em grupos economicamente homogêneos, ou próximos territorialmente, além de estudos em que o Brasil é analisado separadamente, em distintos períodos históricos e procedimentos metodológicos com nuances pontuais entre si, há na literatura uma lacuna no tocante ao período anterior à crise de 2008, que permite ao presente estudo contribuir no sentido de elucidar-se a hipótese de que, antes da referida crise, o Brasil se livrara de sua histórica restrição externa ao crescimento econômico.

\section{Dados e Fontes}

Para o teste empírico foram coletados dados anuais das variáveis PIB, importações, exportações, conta capital, serviços do capital, taxa nominal de câmbio, índice de preços internos do Brasil e dos EUA, ao longo do período compreendido entre 1980 e 2008. Assim, as séries referentes ao PIB, importações gerais e não fatores, exportações gerais e não fatores, conta capital (representada pelo inverso do saldo da conta corrente), e serviços do capital foram extraídos da base estatística da Cepal, denominada CepalStat, enquanto as variáveis taxa nominal de câmbio, IPC Brasil e IPA-EUA foram obtidos junto ao site do FMI, no Internacional Financial Statistics (IFS).

Uma vez que as séries anuais do PIB, exportações, importações, conta capital e serviços do capital encontravam-se expressas em dólares americanos a preços correntes, foi necessário deflacioná-las, o que foi feito utilizando-se o IPA-EUA, com ano base igual a 2005. Já o cálculo da taxa real de câmbio, para o Brasil, foi obtido por meio da formulação $\left(P_{f}^{* E} E / P_{d}\right)$, sendo utilizada como medida de $P_{f}$ os tradables americanos (IPA-EUA) e como medida de $P_{d}$ os non-tradables locais (IPC brasileiro).

\section{Metodologia Empírica}

Para testar a validade da Lei de Thirlwall, nas versões tradicional e estendidas, para o Brasil entre 1980 e 2008, será empregada a linha de teste empírico proposta por McCombie (1989). Como mencionado no capítulo precedente, Carvalho e Lima (2009) apresentam um teste alternativo que possibilita a aplicação desta metodologia desenvolvida por $\mathrm{McCombie}^{6}$. A escolha do período tem como intuito

Esta metodologia também foi empregada por Gouvêa (2010) para a economia brasileira, entre 1962-2006. 
fundamental testar a hipótese de que o crescimento potencial brasileiro, mesmo antes da crise, ainda era condicionado por variáveis relacionadas ao balanço de pagamentos, refletindo-se tal realidade nos números atuais.

Tendo isso em vista, serão descritos os procedimentos de verificação da validade da Lei de Thirlwall. Na lógica desta linha de teste empírico, o primeiro passo consiste na estimação da função de demanda por importações com base na seguinte especificação:

$$
\ln \left(M_{t}\right)=\pi \ln \left(Y_{t}\right)+\varphi \ln \left(P_{f t}+E_{t}-P_{t}\right)
$$

Em que as variáveis são as já definidas na seção Revisão de Literatura.

O procedimento econométrico consistiu no tratamento usual às séries temporais, inicialmente com a aplicação de testes de raiz unitária, a saber: teste $A D F$ (Augmented Dickey Fuller), apresentado em Dickey e Fuller (1979), com possíveis inconvenientes corrigidos pelo teste $(P P)$ apresentado em Phillips e Perron (1988), o teste KPPS como complementar ao $A D F$ e o teste $U R$ (Unit Root), que modela explicitamente a quebra estrutural (ENDERS, 2004). Após verificar a ordem de integração das séries de interesse, sendo as mesmas não estacionárias, o passo seguinte é o teste de cointegração, que possibilita avaliar os mecanismos de curto e longo prazo de séries integradas. No presente estudo será utilizada a metodologia de cointegração conforme Johansen (1995) para testar a existência de alguma relação de longo prazo entre as variáveis.

Assim, uma vez obtidas essas elasticidades para o Brasil entre 1980-2008, o passo subsequente consistirá em utilizar tais estimativas para computar a taxa de crescimento da renda condizente com o equilíbrio do BP, com base nas formulações apresentadas por Thirlwall (1979), Thirlwall e Hussain (1982), Moreno-Brid (2003) e Carvalho e Lima (2007-2009). A elasticidade-renda das importações estimada na equação (14) será substituída nas seis seguintes especificações:

Modelo 1: Lei de Thirlwall Tradicional (LT), versão Thirlwall (1979) - Equilíbrio de Longo Prazo sem Termos de Troca, como na equação (2);

Modelo 2: Modelo 1 incluindo Termos de Troca, equação (3);

Modelo 3: Lei de Thirlwall Estendida, versão Thirlwall e Hussain (1982) Equilíbrio de Longo Prazo incluindo Conta Capital e sem Termos de Troca, de acordo com o estabelecido na equação (5);

Modelo 4: Lei de Thirlwall Estendida, versão Moreno-Brid (2003) - Equilíbrio de Longo Prazo incluindo Conta Capital, Serviços do Capital (explicitamente), sem Termos de Troca e impondo limite à entrada de Capital Externo (manutenção da relação dívida/PIB), ou equação (11); 
Modelo 5: Lei de Thirlwall Estendida, versão Carvalho e Lima (2007-2009) - Equilíbrio de Longo Prazo incluindo Conta Capital, Serviços do Capital (explicitamente), Termos de Troca e não impondo limites à entrada de Capital Externo, de acordo com a equação (12);

Modelo 6: Modelo 5 sem Termos de Troca, equação (13).

As equações encontram-se na Revisão de Literatura, assim como as definições de respectivas variáveis. Tais variáveis têm suas fontes e tratamento listados na seção Dados e Fontes.

Em seguida, as taxas de crescimento previstas por cada um dos modelos teóricos listados e a taxa de crescimento real da economia serão comparadas. Para tal, aplicouse o teste de hipóteses sobre o valor da diferença entre duas médias. A não rejeição da hipótese de proximidade entre ambas as taxas (real e proveniente dos 6 modelos alternativos) indicará a validade do modelo, separadamente para cada especificação.

Vale salientar que a ampliação da LT proposta por Carvalho e Lima (20072009) - modelo 5 - considera todos os componentes do BP: i) comércio internacional, ii) termos de intercâmbio, iii) entrada de capitais (sem a colocação de limites) e iv) pagamento de juros. Sendo assim, esta versão apresenta a vantagem adicional de possibilitar a decomposição da taxa de crescimento da renda compatível com o equilíbrio externo na importância de cada um desses componentes, utilizando-se a equação (12), condizente com a formulação do Modelo 5.

\section{Resultados e Discussões}

A análise para a economia brasileira, ao longo do período 1980-2008, iniciouse com a realização de testes de raiz unitária para verificar a ordem de integração das três séries presentes na função de importação, incluindo os testes ADF, PP, KPSS e UR (com quebra estrutural - Anexo 1). De acordo com os resultados obtidos, não foi possível rejeitar a existência de uma raiz unitária para as variáveis importações, PIB e câmbio real.

Tendo em vista que as variáveis de interesse são integradas de ordem 1, prossegue-se para a estimação da função de importação por meio de técnicas de cointegração conforme Johansen (1995). A escolha do número de defasagens empregadas no modelo foi feita por meio dos critérios de informação AIC e HQ, obtendo-se um VAR de ordem 5, o que equivale um VEC de ordem 4 (ANEXO 1). Com base na análise dos termos deterministas foi escolhido o modelo sem intercepto e sem tendência, que indica uma relação de cointegração, a 5\% de significância. Esta escolha, novamente, é condizente com o modelo de Thirlwall, segundo o qual a ausência de constante dentro do vetor de cointegração possibilitaria que as elasticidades captassem todo o componente estrutural da economia (CARVALHO, 2005). Sendo assim, estimou-se apenas um vetor de cointegração significante, a $1 \%$ e $5 \%$, de acordo com a estatística do Traço e do Autovalor, obtendo-se a seguinte relação de longo prazo: 
Conforme a Tabela 1, o câmbio real pode ser considerado não significativo, a $1 \%$ de significância, na relação de longo prazo. Assim, os resultados obtidos sugerem que a elasticidade-preço não contribuiu para explicar a relação de longo prazo da função de importação. Já a elasticidade-renda da demanda por importações pode ser considerada estatisticamente diferente de zero, a $1 \%$ de significância. Ou seja, o coeficiente da renda apresentou o sinal esperado, mostrando-se significativo para explicar a relação de longo prazo da demanda por importações para o Brasil, entre 1980 e 2008 ?

$$
\operatorname{LnM}(B R)=0,82 \ln P I B(B R)+0,54 \ln E(B R)
$$

Tabela 1: Função de importação para o Brasil (1980-2008)

\begin{tabular}{cc}
\hline Cointegrating Eq: & CointEq1 \\
\hline LN__M_BR_(-1) & 1.000000 \\
LN__PIB_BR_(-1) & $\mathbf{- 0 . 8 2 7 7 8 6}$ \\
& {$[-60.351]$} \\
LN_E_BR_(-1) & $\mathbf{- 0 . 5 4 7 1 2 1}$ \\
& {$[-1.2374]$} \\
Error Correction: & D(LN__M_BR_) \\
CointEq1 & $\mathbf{0 . 1 9 4 7 6 3}$ \\
& {$[0.35696]$} \\
\hline
\end{tabular}

Fonte: Elaboração própria utilizando-se o pacote estatístico Eviews 6. M_BR = importações brasileiras; PIB_BR = Produto Interno Bruto brasileiro; $E_{-} B R=$ taxa de câmbio R $\$ / U S \$$

Com relação às variáveis que se ajustam no curto prazo para restabelecer o equilíbrio de longo prazo, tem-se que apenas o componente da renda pode ser considerado estatisticamente diferente de zero, com características endógenas. Desta forma, se algum choque atinge a função importação tirando-a do equilíbrio de longo prazo, esta variável irá se ajustar para restaurar esse equilíbrio.

A respeito da análise dos resíduos da cointegração, os testes de normalidade e de autocorrelação não rejeitaram a hipótese de normalidade e de ausência de autocorrelação dos resíduos, a 1\% de significância. Esses resultados, portanto, dão suporte ao uso do instrumental de cointegração para a estimação das elasticidades de importação.

Baseadas nas elasticidades-preço e renda da demanda por importações, estimadas por meio de técnicas de cointegração, foram computadas as taxas de crescimento médias para o Brasil, condizentes com as seis formulações do modelo de Thirlwall especificadas na seção metodológica. Em seguida, compararam-se as taxas de crescimento previstas pelos modelos teóricos e a taxa de crescimento observada

7 Carvalho (2005) encontrou resultados semelhantes para a economia brasileira, entre 1930-2004. 
da economia brasileira, entre 1980 e 2008. Para tal, aplicou-se o teste de hipóteses sobre o valor da diferença entre duas médias. A não rejeição da hipótese de proximidade entre ambas as taxas indicará a validade do modelo. Os resultados obtidos para o Brasil estão contidos na Tabela 2, a seguir:

Tabela 2: Resultados da Lei de Thirlwall para o Brasil

\begin{tabular}{c|c|c|c|c|c|c|c}
\cline { 2 - 8 } & Real & Modelo 1 & Modelo 2 & Modelo 3 & Modelo 4 & Modelo 5 & Modelo 6 \\
\hline Crescimento médio 80-08 & $2,5 \%$ & $2,4 \%$ & $3,3 \%$ & $2,2 \%$ & $1,4 \%$ & $4,1 \%$ & $3,1 \%$ \\
\hline t-valor & & 1,3 & 0,3 & 0,9 & 0,7 & $-0,1$ & $-0,2$ \\
\hline
\end{tabular}

Fonte: Estimativa própria com base em dados da Cepal e FMI.

De acordo com a estatística $t$-student, não foi possível rejeitar a hipótese nula de igualdade entre a taxa de crescimento compatível com o equilíbrio do Balanço de Pagamentos e a taxa de crescimento real, a 5\% de significância, para nenhum modelo. Portanto, os resultados obtidos indicam a validade da Lei de Thirlwall para a economia brasileira, nas versões tradicional e estendidas, para o período compreendido entre 1980-2008, ou seja, o crescimento econômico da economia brasileira era condicionado pelas suas relações externas mesmo antes da crise de $2008^{8}$.

Fazendo uma análise mais detalhada, percebe-se que a divergência entre a taxa de crescimento média observada e a estimada, por meio do modelo 1, é bem menor quando comparada à do modelo 2. Isso indica que a introdução dos termos de troca não contribuiu para reduzir a divergência entre a taxa média de crescimento efetiva e a taxa média estimada. Uma vez que, no caso do modelo 2, ocorreu uma superestimação da taxa média de crescimento da renda, para o período em questão, talvez em virtude da elevação dos preços das commodities agrícolas e metálicas nesse ciclo econômico pré-crise, o que reduz a própria relevância estrutural do referido ciclo. A quase igualdade entre a taxa efetiva e a estimada pelo Modelo 1 reforça a dependência do crescimento local às exportações, especialmente as supracitadas, associada à necessidade de importar produtos mais elaborados, seja pela não oferta interna, ou pelo processo de desindustrialização, que atualmente assombra a economia nacional.

A inclusão da conta capital à LT (modelo 3) contribuiu, positivamente, para reduzir a divergência entre as taxas médias de crescimento real e teórica relativamente ao modelo 2. Contudo, a taxa de crescimento média obtida a partir do modelo 1 continua apresentado a maior proximidade referente à taxa real de crescimento da economia brasileira, entre 1980 e 2008. Esta versão ampliada de Thirlwall e Hussain (1982) subestimou a taxa média real de crescimento da renda, para o caso brasileiro, no período analisado, em 0,3 pontos percentuais. Esse acontecimento, mais

8 Carvalho (2005), Vieira (2007), Gouvêa (2010), entre outros, utilizando a mesma metodologia, também encontraram evidencias favoráveis à validade da LT para a economia brasileira. 
uma vez, confirmaria a proposição assumida por Ferreira (2001), de que o fluxo de capitais, apesar de cobrir possíveis déficits da conta corrente, não foi suficiente para impactar a trajetória de crescimento econômico no longo prazo", o que pode ser fruto de um fluxo de capitais muito mais especulativo que produtivo.

A inclusão dos serviços do capital (Modelo 4), explicitamente, e a imposição de limite à entrada de capitais externos, contribuíram para reduzir ainda mais a taxa de crescimento compatível com o equilíbrio externo. Dessa forma, os resultados obtidos sugerem que o modelo teórico que considera o impacto do pagamento de juros externos e assume a hipótese de que o déficit em conta corrente como proporção do PIB é estável, proporcionou uma taxa de crescimento média $(1,4 \%$ a.a $)$ bem abaixo da taxa média real de crescimento (2,5\% a.a) e da taxa média estimada via Modelo 1 (LT original).

Uma possível causa para esta baixa taxa teórica de crescimento (modelo 4), poderia ser a influência negativa do pagamento de juros sobre a trajetória de crescimento econômico brasileiro, ao longo do período de análise, intensificando as restrições decorrentes do Balanço de Pagamentos, reafirmando a evidência sustentada por Elliot e Rhodd (1999) e Moreno-Brid (2003). Outra explicação para a baixa taxa de crescimento estimada poderia residir no fato de se assumir a hipótese de estabilidade da razão dívida/PIB. Os dados referentes à conta corrente e conta capital + financeira como proporção do PIB (Gráfico 1) mostraram que, entre 1980-2009, essa razão não apresentou um comportamento significativamente estável, com leve, mas nítida tendência de crescimento.

Gráfico 1: Indicadores Externos da Economia Brasileira (Em \% do PIB), entre 1980 e 2009. CCA = Conta Capital + Financeira CCO = Conta Corrente

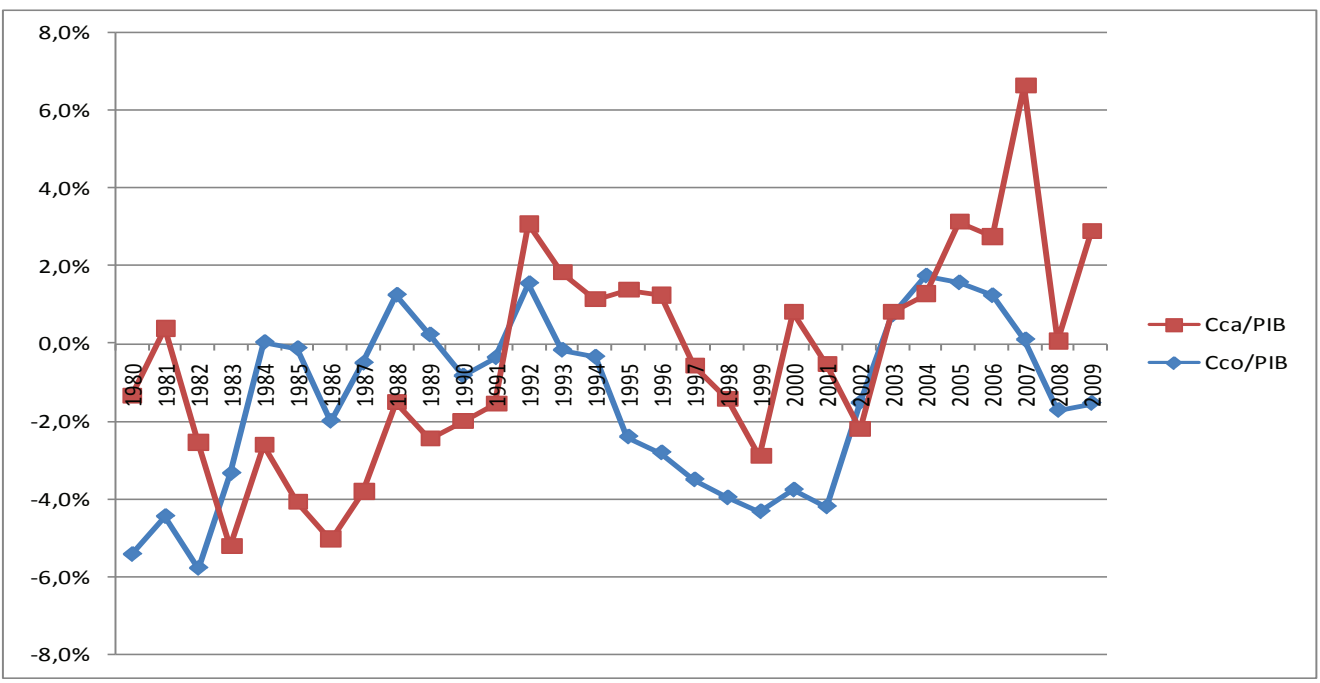

Fonte: Elaboração própria utilizando dados da Cepal - CEPALSTAT -, (2010).

9 Hipótese também verificada por Carvalho (2005) e Vieira (2007) para a economia brasileira. 
Fazendo um paralelo com as taxas de crescimento resultantes do modelo proposto por Carvalho e Lima (2007-2009) - o qual considera o pagamento de juros, mas sem impor limites à entrada de capitais, percebe-se a ocorrência de dois fatos que merecem menção. Em primeiro lugar, esta versão de Moreno-Brid (2003) subestimou tanto o papel dos termos de troca, como da conta capital, pois as taxas médias de crescimento estimadas a partir dos modelos teóricos 5 e 6 se mostraram significativamente superiores ao valor resultante do modelo 4 . Em segundo lugar, a maior parte da divergência entre as taxas estimadas a partir do modelo 4 e as calculadas pelos modelos 5 e 6 parece recair sobre a hipótese adicional, assumida por Moreno-Brid (2003), de estabilidade da razão dívida/PIB, pois esta hipótese se constitui na única diferença entre as formulações estendidas de Carvalho e Lima (2007-2009) e a versão de Moreno-Brid (2003).

A taxa média de crescimento estimada a partir do modelo 5, apesar de não ser estatisticamente diferente da taxa real de crescimento do PIB brasileiro, superestimou a taxa média de crescimento do produto em 1,6 pontos percentuais, para o período em questão. Contudo, esta formulação apresenta a vantagem adicional de decompor o crescimento da renda condizente com o equilíbrio externo, entre os diversos componentes do BP. Assim, para o caso brasileiro foi computada a seguinte decomposição (Tabela 3):

Tabela 3: Contribuição dos componentes do BP no crescimento brasileiro

\begin{tabular}{c|c|c|c|c|c}
\cline { 2 - 6 } & Modelo 5 & Exportações & Termos de troca & Serviço da dívida & Capitais \\
\hline Crescimento médio 80-08 & $4,1 \%$ & $2,6 \%$ & $1,0 \%$ & $-0,7 \%$ & $1,2 \%$ \\
\hline
\end{tabular}

Fonte: Estimativa própria com base em dados da Cepal e FMI.

Conforme os números contidos na Tabela 3, dos 4,1\% do crescimento médio previsto pelo modelo teórico para a economia brasileira, o lado real, dado pela razão entre as elasticidades-renda, respondeu pela maior parte desse crescimento $(2,6 \%)$, provavelmente impulsionado pelo resultado comercial expressivo. Por sua vez, os termos de trocas e os fluxos de capitais contribuíram com 1,0\% e 1,2\%, respectivamente. Já o pagamento de juros restringiu o crescimento médio do produto em -0,7 pontos percentuais, entre 1980 e 2008.

Analisando os modelos que incorporam os serviços da dívida na equação de equilíbrio de longo prazo (modelos 4, 5 e 6), é perceptível, de fato, que o impacto negativo desse componente financeiro, sobre o crescimento do produto, foi reforçado pela imposição de limites à entrada de capital externo. Pois, como constatado previamente, dentre as versões que consideram o pagamento de juros, o modelo de Moreno-Brid (2003) foi o que apresentou a menor taxa de crescimento médio do $\mathrm{PIB}$, relativamente aos modelos que não levam em conta os efeitos dos serviços do capital sobre a trajetória de crescimento das nações (modelos 1, 2 e 3 ).

Tendo como base esses resultados, verifica-se predominância de aspectos comerciais à restrição externa brasileira ao crescimento econômico. Isso ressalta nossa 
dependência de importações elaboradas, sendo essas financiadas com exportações de commodities altamente dependentes de ciclos econômicos favoráveis. No século XXI, tal tendência acentua o processo de desindustrialização, que intensifica essa histórica característica e que deve ser combatida com políticas em prol do adensamento de cadeias produtivas industriais, que, auxiliadas pelo incentivo ao ingresso de capitais produtivos em detrimento dos retornos especulativos, potencializa a quebra da lógica que reflete em elevada conta de serviços de capital e imposição de tetos para endividamento.

\section{Conclusão}

O presente estudo teve como propósito testar a validade da Lei de Thirlwall, nas versões tradicional e estendidas para o Brasil. Tal análise foi feita com o intuito de obter evidências empíricas favoráveis ou não à aplicabilidade da abordagem do crescimento restrito pelo Balanço de Pagamentos, além de testar a hipótese de que o Brasil, apesar de apresentar condição diversa daquela observada nos anos 80 , continua tendo seu crescimento econômico vinculado às suas relações internacionais.

Uma vez obtidas as elasticidades-renda e preço da demanda por importações, o passo subsequente consistiu no cálculo das taxas médias de crescimento do PIB brasileiro, com base nos modelos de Thirlwall (1979), Thirlwall e Hussain (1982), Moreno-Brid (2003) e Carvalho e Lima (2007-2009), para o período compreendido 1980-2008. De acordo com os resultados alcançados, pode-se dizer que a taxa real de crescimento do PIB foi a condizente com o equilíbrio do Balanço de Pagamentos, para todos os modelos empregados.

Resumidamente, podem-se apresentar os seguintes resultados por modelagem específica:

1) Lado comercial: a relação entre a elasticidade-renda da demanda por importações e a taxa de crescimento da demanda externa por exportações, restringiu o crescimento econômico no Brasil, entre 1980 e 2008. Uma razão para isso pode ser encontrada na deterioração da balança comercial em alguns anos, posteriores ao surgimento do MERCOSUL, como consequência da elevação da vinculação econômica relativamente ao setor externo.

2) Termos de trocas: afetaram positivamente a trajetória brasileira de crescimento. Uma explicação para esse evento pode ser encontrada na taxa à qual as exportações são trocadas pelas importações, isto é, no comportamento dos termos de trocas, que experimentou uma melhoria após a criação do MERCOSUL, bloco ao qual o Brasil pertence. Além disso, o crescimento mundial na primeira década do Século XXI aumentou sobremaneira a demanda dos bens exportados pelo país.

3) Fluxos de capitais: não mitigou diretamente as restrições externas ao crescimento de longo prazo. Uma explicação para tal acontecimento pode residir na questão relativa à liberalização financeira ocorrida nos 
anos noventa. Esta não foi suficiente para financiar, com folga, os déficits brasileiros em transações correntes, além do componente especulativo que normalmente está presente nesses fluxos.

4) Pagamento de juros externos e imposição de limites à entrada de capitais: contribuíram negativamente, para o crescimento da economia brasileira no período, conforme expectativa teórica.

Os resultados do estudo apontam para um imprescindível cuidado às relações exteriores, tanto conta corrente quanto conta capital, já que o desenvolvimento brasileiro continua intimamente relacionado às questões externas. $\mathrm{O}$ Brasil, mesmo com resultados favoráveis na primeira década do presente século, não se desvencilhou de velhos estigmas externos, como intensa dependência de exportação de commodities e importação manufatureira, seja por deficiência produtiva seja pela desindustrialização.

\section{Referências}

AVERBUG, A. Abertura e Integração Comercial Brasileira na Década de 90. In: GIAMBIAGI, F. e MOREIRA, M. A Economia Brasileira nos Anos 90. 1. ed. Rio de Janeiro: Banco Nacional de Desenvolvimento Econômico e Social (BNDES), 1999. Rio de Janeiro: BNDES, 1999.

BATISTA, P. Argentina: uma crise paradigmática. Estudos Avançados, v.16, n.44, São Paulo, 2002.

BÉRTOLA, L.; HIGACHI, H.; PORCILE, G. Balance-of-payments-constrained growth in Brazil: a test of Thirwall's Law. Journal of Post Keynesian Economics, v.25, n. 123, 2002.

BRITTO, Gustavo ; MCCOMBIE, John S.L. Thirlwall's law and the long-term equilibrium growth rate: an application to Brazil. Journal of Post Keynesian Economics, v. 32, p. 115-136, 2009. crossref https://doi.org/10.2753/PKE0160-3477320108

CARVALHO, V. A Restrição Externa e a perda de dinamismo da economia brasileira: investigando as relações entre estrutura produtiva e crescimento econômico. Dissertação (Mestrado em Economia) - Programa de Pós-Graduação em Economia, FEA-USP, Universidade de São Paulo, São Paulo, 2005.

CARVALHO, V.; LIMA, G. T. A restrição externa e a perda de dinamismo da economia brasileira: investigando relações entre estrutura produtiva e crescimento econômico. Anais eletrônicos do XXXV Encontro Nacional de Economia, Recife, Dezembro, 2007. Disponível em: http://www.anpec.org.br/.../0009b6780f5f49ff83ac9cacff609070342.pdf. Acessado em: 11/10/2010. 
CARVALHO, V.; LIMA, G. T. Crescimento econômico e estrutura do setor externo: uma análise em painel de dados. Anais eletrônicos do XXXVI Encontro Nacional de Economia, Salvador, Dezembro, 2008. Disponível em: http://www.anpec. org.br/encontro2008/artigos/200807211311370-.pdf. Acessado em: 07/09/2010.

CARVALHO, V.; LIMA, G. T.; SANTOS, A. T. A restrição externa como fator limitante do crescimento econômico brasileiro: um teste empírico. Revista Economia, v.9, p.285-387, 2008.

CARVALHO, V.; LIMA, G. T.; SANTOS, A. T. Estrutura produtiva, restrição externa e crescimento econômico: a experiência brasileira. Economia e Sociedade, v.18, n.1, p. 31-60, 2009. crossref https://doi.org/10.1590/S0104-06182009000100002

COMISIÓN ECONÓMICA PARA AMÉRICA LATINA Y EL CARIBE (CEPAL). Base de datos y publicaciones estadísticas, CEPALSTAT. Disponível em: http://websie.eclac.cl/infest/ajax/cepalstat.asp? carpeta=estadisticas. Acessado em: 05/02/2011.

DICKEY, D.; FULLER, W. Distribution of the estimators for autoregressive time series with a unit root. Journal of the American Statistical Association, v.74, n.336, p.427-41, 1979. crossrefhttps://doi.org/10.1080/01621459.1979.10482531

ELLIOT, D.; RHODD, R. Explaining growth rate differences in bighly indebted countries: an extension to Thirlwall and Hussain. Applied Economics, v.31, 1999.

ENDERS, W. Applied econometric Time Series. New York: John Wiley \& Sons, Second Edition, 2004.

ESTEVES, L. E.; CORREIA, F. M. Crescimento Econômico e lei de Thirlwall: uma análise para economias latino-americanas. Anais eletrônicos do XIII Encontro Nacional de Economia da Região Sul, Porto Alegre, 2010. Disponível em: http://www.ppge.ufrgs.br/anpecsul2010/artigos/20.pdf. Acessado em: 20/11/2010.

FERREIRA, A. A lei de Crescimento de Thirlwall. Dissertação (Mestrado em Economia), Instituto de Economia da Universidade Estadual de Campinas, Campinas, 2001.

GOUVÊA, R. Padrão de especialização produtiva e crescimento econômico sob restrição externa: uma análise empírica. Dissertação (Mestrado em Economia) Programa de Pós-Graduação em Economia, FEA-USP, Universidade de São Paulo, São Paulo, 2010. 
HOLLAND, M.; VIEIRA, F.; CANUTO, O. Economic growth and the balance-ofpayments constraint in Latin America. Investigación Económica, v.LXIII, 2004.

INTERNATIONAL MONETARY FUND (IMF). Base de dados Internacional Financial Statistics (IFS). Disponível em: http://www.ifs.apdi.net/imf/. Acessado em: 05/12/2010.

JAYME JR., F. G. Growth under external constraints in Brazil: a post Keynesian app roach, in HOLT, R.; PRESSMAN, S. (Orgs.). Empirical Post Keynesian Economics: looking at the real world. New York: M. E. Sharp, pp 305-328 (2007)

JOHANSEN, S. Likelibood based inference in cointegrated vector auto-regressive models. Oxford: Oxford University Press, 1995. crossrefhttps://doi. org/10.1093/0198774508.001.0001

LÓPEZ, J.; CRUZ, A. Thirlwall's Law and beyond: the Latin American experience. Journal of Post Keynesian Economics, v.22, n.3, p.477-95, 2000. crossrefhttps:// doi.org/10.1080/01603477.2000.11490253

MAIA, S. F.; NUNES, D. K. N. Abertura Econômica e Crescimento: Abordagem de Thirlwall para Estudos do Desempenho da Balança Comercial Brasileira. Anais eletrônicos do XLIV Congresso da Sociedade Brasileira de Economia e Sociologia Rural, Fortaleza, 2006. Disponível em: www.sober.org.br/palestra/5/698.pdf. Acessado em: 07/02/2011.

McCOMBIE, J. S. L. Thirlwall's law and balance-of-payments-constrained growth: a comment on the debate. Applied Economics, v.21, p.9-20, 1989.

McCOMBIE, J. S. L. On the empirics of balance-of-payments-constrained growth. Journal of Post Keynesian Economics, v.19, n.3, p.345-75, 1997. crossrefhttps:// doi.org/10.1080/01603477.1997.11490116

McCOMBIE, J. S. L. Economic growth and balance of payments constraint revisited. In: Markets, Unemployment and Economic Policy, v.2. Routledge, London, 1997.

McCOMBIE, J. S. L., THIRLWALL A. P. Economic growth and the balance of payments constraint. New York: St. Martin's Press, 1994. crossrefhttps://doi. org/10.1007/978-1-349-23121-8

MEDEIROS, C. Os Dilemas da Integração Sul-Americana. Cadernos do Desenvolvimento. Rio de Janeiro: Centro Internacional Celso Furtado, 2008. 
MORENO-BRID, J. C. On capital flows and the balance-of-payments constrained growth model. Journal of Post Keynesian Economics, v.21, n.2, p. 283-98, 1998-99. crossrefhttps://doi.org/10.1080/01603477.1998.11490194

MORENO-BRID, J. C. Capital flows, interestpayments and the balance-of-payments constrained growth model: a theoretical and empirical analysis. Metroeconomica, v.54, n.2, p.346-65, 2001.

MORENO-BRID, J. C. Capital flows, interest payments and the balance-of-payments constrained growth model: a theoretical and empirical analysis. Metroeconomica, v.54, n.2, p.346-65, 2003. crossrefhttps://doi.org/10.1111/1467-999X.00170

MORENO-BRID, J. C.; PÉREZ, E. Balance of payments constrained growth in Central America: 1950-96. Journal of Post Keynesian Economics, v.22, n.1, p. 13147, 1999. crossref https://doi.org/10.1080/01603477.1999.11490231

NAKABASHI, L.; PORCILE, G. Crescimento da economia brasileira e fluxo de capitais a partir da Lei de Thirlwall: 1968-1980 e 1992-2000. Texto para Discussão CEDEPLAR/UFMG, n.240, p.1-24, 2004.

PHILLIPS, P.; PERRON, P. Testing fot a Unit Root in Time Series Regression. Bio-

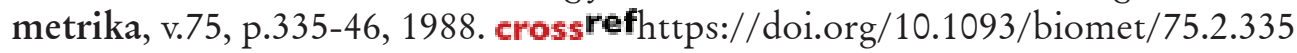

SOARES, C. Modelos de crescimento impulsionados pela demanda: evidências do modelo de Thirlwall para os setores brasileiros. Anais eletrônicos do XIX Simpósio Nacional de Probabilidade e Estatística (SINAPE), São Pedro-SP, 2010. Disponível em: http://www.ime.unicamp.br/sinape/19sinape/node/893. Acessado em: 20/01/2011.

THE WORLD BANK. Base de dados WDI - World Development Indicators. Disponível em: http://data.worldbank.org/data-catalog/world-development-indicators/. Acessado em: 18/01/2011.

TERUCHKIN S.; NIQUE, W. As Relações de Poder Intra-Mercosul. Revista de Administração, v.36, n.3, p.86-94, 2001.

THIRLWALL A. P. The balance of payments constraint as an explanation of international growth rates differences. Banca Nazionale del Lavoro Quarterly Review, v.128, p.45-53, 1979.

THIRLWALL A. P. Balance of Payments Constrained Growth: A Reply. Applied Economics,v.18,p.1259-63,1986.crossrefhttps://doi.org/10.1080/00036848600000001 
THIRLWALL A. P. Professor Krugman's 45-degree rule. Journal of Post Keynesian Economics, v.14, n.1, p.131-47, 1991. crossrefhttps://doi.org/10.1080/01603477. 1991.11489874

THIRLWALL A. P.; HUSSAIN M. N. The balance of payments constraint, capital flows and growth rates differences between developing countries. Oxford Economic Papers, v.34, n.3, p. 498-509, 1982. crossrefhttps://doi.org/10.1093/oxfordjournals.oep.a041565

VALOR (Editorial) - Crise passou a atingir o investimentodireto no país. Valor Econômico, São Paulo, 23/04/2015, Editorial, página A12. Disponível em:< http://www.valor.com.br/opiniao/4017742/crise-passou-atingir-o-investimentodireto-no-pais $>$. Acesso em 24/04/2015.

VIEIRA, F. A. Crescimento Econômico secular no Brasil: uma investigação empírica a partir da abordagem do crescimento com restrição externa. Dissertação (Mestrado em Economia), Instituto de Economia da Universidade Federal de Uberlândia, Uberlândia, 2007.

VIEIRA, F.; VERÍSSIMO, M. Crescimento econômico em economias emergentes selecionadas: Brasil, Rússia, Índia, China (BRIC) e África do Sul. Economia e Sociedade, v. 18, n.3, p. 513-46, 2009. crossref https://doi.org/10.1590/S010406182009000300004 


\section{Anexo 1}

\section{Testes ADF - 1 Raiz Unitária contra 0 Raízes Unitárias}

\begin{tabular}{|c|c|c|c|c|c|}
\hline \multicolumn{6}{|c|}{ Testes de Raiz Unitária para as Variáveis em Nível } \\
\hline \multirow{2}{*}{\multicolumn{2}{|c|}{ País Variáveis }} & \multicolumn{3}{|c|}{ Modelo } & \multirow{2}{*}{ Teste ADF (2 lags) } \\
\hline & & Com C \& Trend & Com C & Sem C ou Trend & \\
\hline \multirow{7}{*}{ Brasil } & $\operatorname{Ln}(\mathrm{PIB})$ & $\begin{array}{l}\text { Sim } \\
\text { Não } \\
\text { Não }\end{array}$ & $\begin{array}{l}\text { Não } \\
\text { Sim } \\
\text { Não }\end{array}$ & $\begin{array}{l}\text { Não } \\
\text { Não } \\
\text { Sim* }\end{array}$ & $\begin{array}{l}\text { Aceita } 1 \text { RU a } 1 \%, 5 \% \text { e } 10 \% \\
\text { Aceita } 1 \text { RU a } 1 \%, 5 \% \text { e } 10 \% \\
\text { Aceita } 1 \text { RU a } 1 \%, 5 \% \text { e } 10 \%\end{array}$ \\
\hline & $\operatorname{Ln}(\mathrm{M})$ & $\begin{array}{l}\text { Sim } \\
\text { Não } \\
\text { Não }\end{array}$ & $\begin{array}{l}\text { Não } \\
\text { Sim } \\
\text { Não }\end{array}$ & $\begin{array}{l}\text { Não } \\
\text { Não } \\
\text { Sim* }\end{array}$ & $\begin{array}{l}\text { Aceita } 1 \text { RU a } 1 \%, 5 \% \text { e } 10 \% \\
\text { Aceita } 1 \text { RU a } 1 \%, 5 \% \text { e } 10 \% \\
\text { Aceita } 1 \text { RU a } 1 \%, 5 \% \text { e } 10 \%\end{array}$ \\
\hline & Ln (M1) & $\begin{array}{l}\text { Sim } \\
\text { Não } \\
\text { Não }\end{array}$ & $\begin{array}{l}\text { Não } \\
\text { Sim } \\
\text { Não }\end{array}$ & $\begin{array}{l}\text { Não } \\
\text { Não } \\
\text { Sim* }\end{array}$ & $\begin{array}{l}\text { Aceita } 1 \text { RU a } 1 \%, 5 \% \text { e } 10 \% \\
\text { Aceita } 1 \text { RU a } 1 \%, 5 \% \text { e } 10 \% \\
\text { Aceita } 1 \text { RU a } 1 \%, 5 \% \text { e } 10 \%\end{array}$ \\
\hline & $\operatorname{Ln}(X)$ & $\begin{array}{l}\text { Sim } \\
\text { Não } \\
\text { Não }\end{array}$ & $\begin{array}{l}\text { Não } \\
\text { Sim* } \\
\text { Não }\end{array}$ & $\begin{array}{l}\text { Não } \\
\text { Não } \\
\text { Sim }\end{array}$ & $\begin{array}{l}\text { Aceita } 1 \text { RU a } 1 \%, 5 \% \text { e } 10 \% \\
\text { Aceita } 1 \text { RU a } 1 \%, 5 \% \text { e } 10 \% \\
\text { Aceita } 1 \text { RU a } 1 \%, 5 \% \text { e } 10 \%\end{array}$ \\
\hline & Ln (X1) & $\begin{array}{l}\text { Sim } \\
\text { Não } \\
\text { Não }\end{array}$ & $\begin{array}{l}\text { Não } \\
\text { Sim* } \\
\text { Não }\end{array}$ & $\begin{array}{l}\text { Não } \\
\text { Não } \\
\text { Sim }\end{array}$ & $\begin{array}{l}\text { Aceita } 1 \text { RU a } 1 \%, 5 \% \text { e } 10 \% \\
\text { Aceita } 1 \text { RU a } 1 \%, 5 \% \text { e } 10 \% \\
\text { Aceita } 1 \text { RU a } 1 \%, 5 \% \text { e } 10 \%\end{array}$ \\
\hline & $\operatorname{Ln}(\mathrm{e})$ & $\begin{array}{l}\text { Sim } \\
\text { Não } \\
\text { Não }\end{array}$ & $\begin{array}{l}\text { Não } \\
\text { Sim } \\
\text { Não }\end{array}$ & $\begin{array}{l}\text { Não } \\
\text { Não } \\
\text { Sim* }\end{array}$ & $\begin{array}{l}\text { Aceita } 1 \text { RU a } 1 \%, 5 \% \text { e } 10 \% \\
\text { Aceita } 1 \text { RU a } 1 \%, 5 \% \text { e } 10 \% \\
\text { Aceita } 1 \text { RU a } 1 \%, 5 \% \text { e } 10 \%\end{array}$ \\
\hline & $\operatorname{Ln}(\mathrm{K}-\mathrm{R})$ & $\begin{array}{l}\text { Sim } \\
\text { Não } \\
\text { Não }\end{array}$ & $\begin{array}{l}\text { Não } \\
\text { Sim* } \\
\text { Não }\end{array}$ & $\begin{array}{l}\text { Não } \\
\text { Não } \\
\text { Sim }\end{array}$ & $\begin{array}{l}\text { Aceita } 0 \text { RU a } 1 \%, 5 \% \text { e } 10 \% \\
\text { Aceita } 0 \text { RU a } 1 \%, 5 \% \text { e } 10 \% \\
\text { Aceita } 0 \text { RU a } 1 \%, 5 \% \text { e } 10 \%\end{array}$ \\
\hline
\end{tabular}

*Modelo Significativo

C: Constante (Cte)

Trend: Tendência

PIB: Renda Interna

M: Importações de bens e serviços em geral

M1: Importações de bens e serviços não fatores

$\mathrm{X}$ : Exportações de bens e serviços em geral

$\mathrm{X} 1$ : Exportações de bens e serviços não fatores

e: Taxa Real de Câmbio

K-R: Componente Financeiro

Conclusão: De acordo com a tabela acima, é possível Não Rejeitar a hipótese nula de 1 Raiz Unitária, a 1\%, 5\% e 10\% de significância, para as variáveis Renda In- 
terna, Importações de bens e serviços em geral, Importações de bens e serviços não fatores, Exportações de bens e serviços em geral, Exportações de bens e serviços não fatores e Taxa Real de Câmbio. Por sua vez, não é possível Rejeitar a hipótese alternativa de 0 Raiz Unitária, a 1\%, 5\% e 10\% de significância, para a série Componente Financeiro, indicando que esta variável é estacionária.

\section{Testes Phillips-Perrón - 1 Raiz Unitária contra 0 Raízes Unitárias}

\begin{tabular}{|c|c|c|c|c|c|}
\hline \multicolumn{6}{|c|}{ Testes de Raiz Unitária para as Variáveis em Nível } \\
\hline \multirow{2}{*}{\multicolumn{2}{|c|}{ País Variáveis }} & \multicolumn{3}{|c|}{ Modelo } & \multirow{2}{*}{ Teste PP (Newey-West 3) } \\
\hline & & Com C \& Trend & Com C & Sem C ou Trend & \\
\hline \multirow{7}{*}{ Brasil } & $\operatorname{Ln}(\mathrm{PIB})$ & $\begin{array}{l}\text { Sim } \\
\text { Não } \\
\text { Não }\end{array}$ & $\begin{array}{l}\text { Não } \\
\text { Sim } \\
\text { Não }\end{array}$ & $\begin{array}{l}\text { Não } \\
\text { Não } \\
\text { Sim }\end{array}$ & $\begin{array}{l}\text { Aceita } 1 \text { RU a } 1 \%, 5 \% \text { e } 10 \% \\
\text { Aceita } 1 \text { RU a } 1 \%, 5 \% \text { e } 10 \% \\
\text { Aceita } 1 \text { RU a } 1 \%, 5 \% \text { e } 10 \%\end{array}$ \\
\hline & $\operatorname{Ln}(\mathrm{M})$ & $\begin{array}{l}\text { Sim } \\
\text { Não } \\
\text { Não }\end{array}$ & $\begin{array}{l}\text { Não } \\
\text { Sim } \\
\text { Não }\end{array}$ & $\begin{array}{l}\text { Não } \\
\text { Não } \\
\text { Sim }\end{array}$ & $\begin{array}{l}\text { Aceita } 1 \text { RU a } 1 \%, 5 \% \text { e } 10 \% \\
\text { Aceita } 1 \text { RU a } 1 \%, 5 \% \text { e } 10 \% \\
\text { Aceita } 1 \text { RU a } 1 \%, 5 \% \text { e } 10 \%\end{array}$ \\
\hline & Ln (M1) & $\begin{array}{l}\text { Sim } \\
\text { Não } \\
\text { Não }\end{array}$ & $\begin{array}{l}\text { Não } \\
\text { Sim } \\
\text { Não }\end{array}$ & $\begin{array}{l}\text { Não } \\
\text { Não } \\
\text { Sim }\end{array}$ & $\begin{array}{l}\text { Aceita } 1 \text { RU a } 1 \%, 5 \% \text { e } 10 \% \\
\text { Aceita } 1 \text { RU a } 1 \%, 5 \% \text { e } 10 \% \\
\text { Aceita } 1 \text { RU a } 1 \%, 5 \% \text { e } 10 \%\end{array}$ \\
\hline & $\operatorname{Ln}(\mathrm{X})$ & $\begin{array}{l}\text { Sim } \\
\text { Não } \\
\text { Não }\end{array}$ & $\begin{array}{l}\text { Não } \\
\text { Sim } \\
\text { Não }\end{array}$ & $\begin{array}{l}\text { Não } \\
\text { Não } \\
\text { Sim }\end{array}$ & $\begin{array}{l}\text { Aceita } 1 \text { RU a } 1 \%, 5 \% \text { e } 10 \% \\
\text { Aceita } 1 \text { RU a } 1 \%, 5 \% \text { e } 10 \% \\
\text { Aceita } 1 \text { RU a } 1 \%, 5 \% \text { e } 10 \%\end{array}$ \\
\hline & $\operatorname{Ln}(\mathrm{X} 1)$ & $\begin{array}{l}\text { Sim } \\
\text { Não } \\
\text { Não }\end{array}$ & $\begin{array}{l}\text { Não } \\
\text { Sim } \\
\text { Não }\end{array}$ & $\begin{array}{l}\text { Não } \\
\text { Não } \\
\text { Sim }\end{array}$ & $\begin{array}{l}\text { Aceita } 1 \text { RU a } 1 \%, 5 \% \text { e } 10 \% \\
\text { Aceita } 1 \text { RU a } 1 \%, 5 \% \text { e } 10 \% \\
\text { Aceita } 1 \text { RU a } 1 \%, 5 \% \text { e } 10 \%\end{array}$ \\
\hline & $\operatorname{Ln}(\mathrm{e})$ & $\begin{array}{l}\text { Sim } \\
\text { Não } \\
\text { Não }\end{array}$ & $\begin{array}{l}\text { Não } \\
\text { Sim } \\
\text { Não }\end{array}$ & $\begin{array}{l}\text { Não } \\
\text { Não } \\
\text { Sim }\end{array}$ & $\begin{array}{l}\text { Aceita } 1 \text { RU a } 1 \%, 5 \% \text { e } 10 \% \\
\text { Aceita } 1 \text { RU a } 1 \%, 5 \% \text { e } 10 \% \\
\text { Aceita } 1 \text { RU a } 1 \%, 5 \% \text { e } 10 \%\end{array}$ \\
\hline & $\operatorname{Ln}(\mathrm{K}-\mathrm{R})$ & $\begin{array}{l}\text { Sim } \\
\text { Não } \\
\text { Não }\end{array}$ & $\begin{array}{l}\text { Não } \\
\text { Sim } \\
\text { Não }\end{array}$ & $\begin{array}{l}\text { Não } \\
\text { Não } \\
\text { Sim }\end{array}$ & $\begin{array}{l}\text { Aceita } 0 \text { RU a } 1 \%, 5 \% \text { e } 10 \% \\
\text { Aceita } 0 \text { RU a } 1 \%, 5 \% \text { e } 10 \% \\
\text { Aceita } 0 \text { RU a } 1 \%, 5 \% \text { e } 10 \%\end{array}$ \\
\hline
\end{tabular}

C: Constante (Cte)

Trend: Tendência

PIB: Renda Interna

M: Importações de bens e serviços em geral

M1: Importações de bens e serviços não fatores

$\mathrm{X}$ : Exportações de bens e serviços em geral

$\mathrm{X} 1$ : Exportações de bens e serviços não fatores

e: Taxa Real de Câmbio

K-R: Componente Financeiro 
Conclusão: Tendo em vista as estatísticas apresentadas, o teste PP proporcionou os mesmos resultados do teste ADF para as variáveis Renda Interna, Importações de bens e serviços em geral, Importações de bens e serviços não fatores, Exportações de bens e serviços em geral, Exportações de bens e serviços não fatores e Taxa Real de Câmbio. Assim, em todos os casos não foi possível Rejeitar a hipótese nula de 1 Raiz Unitária, a 1\%, 5\% e 10\% de significância. Analogamente ao teste anterior, não foi possível Rejeitar a hipótese alternativa de 0 Raiz Unitária, a 1\%, $5 \%$ e $10 \%$ de significância, para a série Componente Financeiro, indicando que esta variável é estacionária.

\section{Testes KPSS - 0 Raízes Unitárias contra 1 Raiz Unitária}

\begin{tabular}{|c|c|c|c|c|c|}
\hline \multicolumn{6}{|c|}{ Testes de Raiz Unitária para as Variáveis em Nível } \\
\hline \multirow{2}{*}{\multicolumn{2}{|c|}{ País Variáveis }} & \multicolumn{2}{|c|}{ Modelo } & \multirow{2}{*}{ Teste PP (Newey-West 3) } & \multirow{2}{*}{ Conclusão } \\
\hline & & Com C \& Trend & Com C & & \\
\hline \multirow{7}{*}{ Brasil } & $\operatorname{Ln}(\mathrm{PIB})$ & $\begin{array}{l}\text { Sim } \\
\text { Não }\end{array}$ & $\begin{array}{l}\text { Não } \\
\text { Sim }\end{array}$ & $\begin{array}{c}\text { Aceita } 0 \text { RU a } 1 \%, 5 \% \text { e } 10 \% \\
\text { Aceita } 1 \text { RU a } 5 \% \text { e } 10 \%\end{array}$ & 1 RU Cte \\
\hline & $\operatorname{Ln}(\mathrm{M})$ & $\begin{array}{l}\text { Sim } \\
\text { Não }\end{array}$ & $\begin{array}{l}\text { Não } \\
\text { Sim }\end{array}$ & $\begin{array}{c}\text { Aceita } 0 \text { RU a } 1 \%, 5 \% \text { e } 10 \% \\
\text { Aceita } 1 \text { RU a } 5 \% \text { e } 10 \%\end{array}$ & 1 RU Cte \\
\hline & $\operatorname{Ln}(\mathrm{M} 1)$ & $\begin{array}{l}\text { Sim } \\
\text { Não }\end{array}$ & $\begin{array}{l}\text { Não } \\
\text { Sim }\end{array}$ & $\begin{array}{c}\text { Aceita } 0 \text { RU a } 1 \%, 5 \% \text { e } 10 \% \\
\text { Aceita } 1 \text { RU a } 5 \% \text { e } 10 \%\end{array}$ & 1 RU Cte \\
\hline & $\operatorname{Ln}(\mathrm{X})$ & $\begin{array}{l}\text { Sim } \\
\text { Não }\end{array}$ & $\begin{array}{l}\text { Não } \\
\text { Sim }\end{array}$ & $\begin{array}{l}\text { Aceita } 1 \text { RU a } 5 \% \text { e } 10 \% \\
\text { Aceita } 1 \text { RU a } 5 \% \text { e } 10 \%\end{array}$ & $1 \mathrm{RU}$ \\
\hline & $\operatorname{Ln}(\mathrm{X} 1)$ & $\begin{array}{l}\text { Sim } \\
\text { Não }\end{array}$ & $\begin{array}{l}\text { Não } \\
\text { Sim }\end{array}$ & $\begin{array}{l}\text { Aceita } 1 \text { RU a } 5 \% \text { e } 10 \% \\
\text { Aceita } 1 \text { RU a } 5 \% \text { e } 10 \%\end{array}$ & $1 \mathrm{RU}$ \\
\hline & $\operatorname{Ln}(\mathrm{e})$ & $\begin{array}{l}\text { Sim } \\
\text { Não }\end{array}$ & $\begin{array}{l}\text { Não } \\
\text { Sim }\end{array}$ & $\begin{array}{c}\text { Aceita } 0 \text { RU a } 1 \%, 5 \% \text { e } 10 \% \\
\text { Aceita } 1 \text { RU a } 10 \%\end{array}$ & 1 RU Cte \\
\hline & $\operatorname{Ln}(\mathrm{K}-\mathrm{R})$ & $\begin{array}{l}\text { Sim } \\
\text { Não }\end{array}$ & $\begin{array}{l}\text { Não } \\
\text { Sim }\end{array}$ & $\begin{array}{l}\text { Aceita } 0 \text { RU a } 1 \%, 5 \% \text { e } 10 \% \\
\text { Aceita } 0 \text { RU a } 1 \% 5 \% \text { e } 10 \%\end{array}$ & O RU \\
\hline
\end{tabular}

C: Constante (Cte)

Trend: Tendência

PIB: Renda Interna

M: Importações de bens e serviços em geral

M1: Importações de bens e serviços não fatores

$\mathrm{X}$ : Exportações de bens e serviços em geral

$\mathrm{X} 1$ : Exportações de bens e serviços não fatores

e: Taxa Real de Câmbio

K-R: Componente Financeiro 
Conclusão: Em concordância com os testes precedentes, não foi possível Rejeitar novamente a hipótese alternativa de que existe 1 Raiz Unitária, a 5\% e/ ou a 10\% de significância, para as variáveis Renda Interna, Importações de bens e serviços em geral, Importações de bens e serviços não fatores, Exportações de bens e serviços em geral, Exportações de bens e serviços não fatores e Taxa Real de Câmbio. Da mesma forma, não foi possível Rejeitar a hipótese nula de 0 Raiz Unitária, a $1 \%, 5 \%$ e $10 \%$ de significância, para a série Componente Financeiro, indicando que esta variável é estacionária.

\section{Testes UR com Quebra Estrutural - 1 Raiz Unitária contra 0 Raízes Unitárias}

\begin{tabular}{|c|c|c|c|c|}
\hline \multicolumn{5}{|c|}{ Testes de Raiz Unitária para as Variáveis em Nível } \\
\hline \multirow{2}{*}{\multicolumn{2}{|c|}{ País Variáveis }} & \multicolumn{2}{|c|}{ Modelo } & \multirow{3}{*}{$\begin{array}{c}\text { Teste PP (Newey-West 3) } \\
\text { Aceita } 1 \text { RU a } 1 \%, 5 \% \text { e } 10 \% \\
\text { Aceita } 1 \text { RU a } 1 \%, 5 \% \text { e } 10 \%\end{array}$} \\
\hline & & Com C \& Trend & Com C & \\
\hline \multirow{7}{*}{ Brasil } & $\operatorname{Ln}(\mathrm{PIB})$ & $\begin{array}{l}\text { Sim } \\
\text { Não }\end{array}$ & $\begin{array}{l}\text { Não } \\
\text { Sim }\end{array}$ & \\
\hline & $\operatorname{Ln}(\mathrm{M})$ & $\begin{array}{l}\text { Sim } \\
\text { Não }\end{array}$ & $\begin{array}{l}\text { Não } \\
\text { Sim }\end{array}$ & $\begin{array}{l}\text { Aceita } 1 \text { RU a } 1 \%, 5 \% \text { e } 10 \% \\
\text { Aceita } 1 \text { RU a } 1 \%, 5 \% \text { e } 10 \%\end{array}$ \\
\hline & Ln (M1) & $\begin{array}{l}\text { Sim } \\
\text { Não }\end{array}$ & $\begin{array}{l}\text { Não } \\
\text { Sim }\end{array}$ & $\begin{array}{l}\text { Aceita } 1 \text { RU a } 1 \%, 5 \% \text { e } 10 \% \\
\text { Aceita } 1 \text { RU a } 1 \%, 5 \% \text { e } 10 \%\end{array}$ \\
\hline & $\operatorname{Ln}(\mathrm{X})$ & $\begin{array}{l}\text { Sim } \\
\text { Não }\end{array}$ & $\begin{array}{l}\text { Não } \\
\text { Sim }\end{array}$ & $\begin{array}{l}\text { Aceita } 1 \text { RU a } 1 \%, 5 \% \text { e } 10 \% \\
\text { Aceita } 1 \text { RU a } 1 \%, 5 \% \text { e } 10 \%\end{array}$ \\
\hline & $\operatorname{Ln}(\mathrm{X} 1)$ & $\begin{array}{l}\text { Sim } \\
\text { Não }\end{array}$ & $\begin{array}{l}\text { Não } \\
\text { Sim }\end{array}$ & $\begin{array}{l}\text { Aceita } 1 \text { RU a } 1 \%, 5 \% \text { e } 10 \% \\
\text { Aceita } 1 \text { RU a } 1 \%, 5 \% \text { e } 10 \%\end{array}$ \\
\hline & $\operatorname{Ln}(\mathrm{e})$ & $\begin{array}{l}\text { Sim } \\
\text { Não }\end{array}$ & $\begin{array}{l}\text { Não } \\
\text { Sim }\end{array}$ & $\begin{array}{l}\text { Aceita } 1 \text { RU a } 1 \%, 5 \% \text { e } 10 \% \\
\text { Aceita } 1 \text { RU a } 1 \%, 5 \% \text { e } 10 \%\end{array}$ \\
\hline & $\operatorname{Ln}(\mathrm{K}-\mathrm{R})$ & $\begin{array}{l}\text { Sim } \\
\text { Não }\end{array}$ & $\begin{array}{l}\text { Não } \\
\text { Sim }\end{array}$ & $\begin{array}{l}\text { Aceita } 1 \text { RU a } 1 \%, 5 \% \text { e } 10 \% \\
\text { Aceita } 1 \text { RU a } 1 \%, 5 \% \text { e } 10 \%\end{array}$ \\
\hline
\end{tabular}

C: Constante (Cte)

Trend: Tendência

PIB: Renda Interna

M: Importações de bens e serviços em geral

M1: Importações de bens e serviços não fatores

$\mathrm{X}$ : Exportações de bens e serviços em geral

X1: Exportações de bens e serviços não fatores

e: Taxa Real de Câmbio

K-R: Componente Financeiro 
Conclusão: Em concordância com os testes precedentes, não foi possível Rejeitar novamente a hipótese alternativa de que existe 1 Raiz Unitária, a 5\% e a 10\% de significância, para as variáveis Renda Interna, Importações de bens e serviços em geral, Importações de bens e serviços não fatores, Exportações de bens e serviços em geral, Exportações de bens e serviços não fatores, Taxa Real de Câmbio e Componente Financeiro.

\section{Seleção da ordem do VAR}

VAR Lag Order Selection Criteria

Endogenous variables: LN_M_BR_LN_PIB_BR_LN_E_BR_

Exogenous variables: $\mathrm{C}$

Date: 11/01/11Time: 14:45

Sample: 19802008

Included observations: 24

\begin{tabular}{c|c|c|c|c|c|c}
\hline Lag & LogL & LR & FPE & AIC & SC & HQ \\
\hline 0 & -4.235235 & NA & 0.000367 & 0.602936 & 0.750193 & 0.642003 \\
\hline 1 & 59.56169 & 106.3282 & $3.85 \mathrm{e}-06$ & -3.963474 & $-3.374447 *$ & -3.807205 \\
\hline 2 & 71.52281 & 16.94493 & $3.14 \mathrm{e}-06$ & -4.210234 & -3.179437 & -3.936764 \\
\hline 3 & 79.00808 & 8.732808 & $3.97 \mathrm{e}-06$ & -4.084006 & -2.611439 & -3.693334 \\
\hline 4 & 98.15536 & $17.55167^{*}$ & $2.14 \mathrm{e}-06 *$ & -4.929613 & -3.015276 & -4.421739 \\
\hline 5 & 111.2575 & 8.734737 & $2.36 \mathrm{e}-06$ & $-5.271455^{*}$ & -2.915348 & $-4.646379 *$ \\
\hline
\end{tabular}

* indicates lag order selected by the criterion

LR: sequential modified LR test statistic (each test at 5\% level)

FPE: Final prediction error

AIC: Akaike information criterion

SC: Schwarz information criterion

HQ: Hannan-Quinn information criterion

Conclusão: Optou-se pelos critérios tradicionais AIC e HQ para a seleção da ordem do VAR, obtendo-se um VAR de ordem 5, o que equivale a um VEC de ordem 4.

\section{Escolha dos termos deterministas}

Date: 11/01/11Time: 14:46

Sample: 19802008

Included observations: 24

Series: LN_M_BR_LN_PIB_BR_LN_E_BR_

Lags interval: 1 to 4

Selected ( 0.05 level*) Number of Cointegrating Relations by Model 


\begin{tabular}{c|c|c|c|c|c}
\hline Data Trend: & None & None & Linear & Linear & Quadratic \\
\hline Test Type & No Intercept & Intercept & Intercept & Intercept & Intercept \\
\hline & No Trend & No Trend & No Trend & Trend & Trend \\
\hline Trace & 1 & 1 & 1 & 2 & 3 \\
\hline Max-Eig & 1 & 1 & 1 & 2 & 3 \\
\hline
\end{tabular}

*Critical values based on Osterwald-Lenum (1992)

Conclusão: Com base nos resultados obtidos, optou-se pelo modelo 1 (sem intercepto e sem tendência), que indica a existência de uma relação de cointegração, a 5\% de significância. Essa escolha é compatível com o modelo de Thirlwall, segundo o qual a ausência de constante dentro do vetor de cointegração possibilitaria que as elasticidades captassem todo o componente estrutural da economia.

\section{Vetor de Cointegração e Testes de Cointegração}

Date: 11/01/11Time: 14:46

Sample (adjusted): 19852008

Included observations: 24 after adjustments

Trend assumption: No deterministic trend

Series: LN_M_BR_LN_PIB_BR_LN_E_BR_

Lags interval (in first differences): 1 to 4

\begin{tabular}{ccccc}
$\begin{array}{c}\text { Hypothesized } \\
\text { No. of CE }(\mathrm{s})\end{array}$ & Eigenvalue & $\begin{array}{c}\text { Trace } \\
\text { Statistic }\end{array}$ & $\begin{array}{c}5 \text { Percent } \\
\text { Critical Value }\end{array}$ & $\begin{array}{c}\text { 1 Percent } \\
\text { Critical Value }\end{array}$ \\
\hline \hline None $* *$ & 0.664149 & 32.08565 & 24.31 & 29.75 \\
At most 1 & 0.216085 & 5.899551 & 12.53 & 16.31 \\
At most 2 & 0.002357 & 0.056643 & 3.84 & 6.51 \\
\hline
\end{tabular}

Trace test indicates 1 cointegrating equation(s) at both 5\% and 1\% levels $*(* *)$ denotes rejection of the hypothesis at the $5 \%(1 \%)$ level

\begin{tabular}{ccccc}
\hline \hline $\begin{array}{c}\text { Hypothesized } \\
\text { No. of CE }(\mathrm{s})\end{array}$ & Eigenvalue & $\begin{array}{c}\text { Max-Eigen } \\
\text { Statistic }\end{array}$ & $\begin{array}{c}5 \text { Percent } \\
\text { Critical Value }\end{array}$ & $\begin{array}{c}\text { 1 Percent } \\
\text { Critical Value }\end{array}$ \\
\hline \hline None $* *$ & 0.664149 & 26.18610 & 17.89 & 22.99 \\
At most 1 & 0.216085 & 5.842908 & 11.44 & 15.69 \\
At most 2 & 0.002357 & 0.056643 & 3.84 & 6.51 \\
\hline \hline
\end{tabular}

Max-eigenvalue test indicates 1 cointegrating equation(s) at both $5 \%$ and $1 \%$ levels $*(* *)$ denotes rejection of the hypothesis at the $5 \%(1 \%)$ level 
Unrestricted Cointegrating Coefficients (normalized by $b *$ S11*b=I):

\begin{tabular}{ccc}
$\mathrm{LN}_{\overline{-} \mathrm{M}_{-} \mathrm{BR}}$ & $\mathrm{LN}_{\overline{16}} \mathrm{PIB}_{-} \mathrm{BR}$ & $\mathrm{LN}_{\overline{-}} \mathrm{E}_{-} \mathrm{BR}$ \\
-19.89346 & 16.46753 & 10.88413 \\
7.800264 & -6.423143 & -2.539494 \\
16.91882 & -14.15272 & -5.610995 \\
\hline
\end{tabular}

Unrestricted Adjustment Coefficients (alpha):

\begin{tabular}{llrr}
\hline D(LN_M_BR_ $)$ & -0.009790 & 0.039125 & -0.001641 \\
D(LN_PIB_BR_) & -0.026586 & 0.049444 & -0.000519 \\
D(LN_E_BR_) & -0.098511 & -0.015391 & -0.000204 \\
\hline
\end{tabular}

1 Cointegrating Equation(s): $\quad$ Log likelihood $\quad 100.9679$

Normalized cointegrating coefficients (standard error in parentheses)

\begin{tabular}{|c|c|}
\hline $\mathrm{CN}_{1.000000}^{\mathrm{M}} \mathrm{BR}$ & $\begin{array}{c}\mathrm{LN}_{\overline{0}} \text { PIB_BR_- } \\
-0.827786 \\
(0.00137)\end{array}$ \\
\hline
\end{tabular}

Adjustment coefficients (standard error in parentheses)

\begin{tabular}{cc} 
D(LN_M_BR_ $)$ & 0.194763 \\
& $(0.54562)$ \\
$\mathrm{D}\left(\mathrm{LN} \_\right.$_PIB_BR $)$ & 0.052881 \\
& $(0.65115)$ \\
$\mathrm{D}\left(\mathrm{LN} \_\right.$E_BR_ $)$ & 0.059718 \\
& $(0.46543)$ \\
\hline
\end{tabular}

$(0.46543)$

Conclusão: De acordo com as estatísticas do Traço e do Autovalor, é possível aceitar a hipótese de pelo menos 1 vetor de cointegração, a $1 \%$ e $5 \%$ de significância.

Assim, obtém-se a relação de Longo Prazo:

$$
\ln \mathrm{M}(\mathrm{BR})=0,82 \ln \mathrm{PIB}(\mathrm{BR})+0,54 \ln \mathrm{E}(\mathrm{BR})
$$

Vector Error Correction Estimates

Date: 11/01/11Time: 14:48

Sample (adjusted): 19852008

Included observations: 24 after adjustments

Standard errors in ( ) \& t-statistics in [] 


\begin{tabular}{cc}
\hline Cointegrating Eq: & CointEq1 \\
\hline \hline LN_M_BR_(-1) & 1.000000 \\
LN_PIB_BR_(-1) & -0.827786 \\
& $(0.00137)$ \\
& {$[-60.351]$} \\
& -0.547121 \\
LN_E_BR_(-1) & $(0.03174)$ \\
& {$[-1.2374]$} \\
\hline
\end{tabular}

\begin{tabular}{|c|c|c|c|}
\hline Error Correction: & $\mathrm{D}\left(\mathrm{LN} \_\mathrm{M} \_\mathrm{BR} \_\right)$ & $\mathrm{D}\left(\mathrm{LN} \_\mathrm{PIB} \_\mathrm{BR} \_\right)$ & $\mathrm{D}\left(\mathrm{LN} \_\mathrm{E} \_\mathrm{BR} \_\right)$ \\
\hline CointEq1 & $\begin{array}{c}0.194763 \\
(0.54562) \\
{[0.35696]}\end{array}$ & $\begin{array}{c}0.052881 \\
(0.65115) \\
{[9.81222]}\end{array}$ & $\begin{array}{c}0.059718 \\
(0.46543) \\
{[0.21052]}\end{array}$ \\
\hline R-squared & 0.316839 & 0.422635 & 0.903537 \\
\hline Adj. R-squared & -0.428427 & -0.207218 & 0.798305 \\
\hline Sum sq. resids & 0.198589 & 0.282847 & 0.144510 \\
\hline S.E. equation & 0.134364 & 0.160354 & 0.114618 \\
\hline F-statistic & 0.425136 & 0.671006 & 8.586141 \\
\hline Log likelihood & 23.48031 & 19.23630 & 27.29497 \\
\hline Akaike AIC & -0.873360 & -0.519692 & -1.191247 \\
\hline Schwarz SC & -0.235247 & 0.118420 & -0.553135 \\
\hline Mean dependent & 0.066624 & 0.060992 & 0.013089 \\
\hline S.D. dependent & 0.112422 & 0.145944 & 0.255215 \\
\hline
\end{tabular}

Determinant resid covariance (dof adj.)

Determinant resid covariance

Log likelihood

Akaike information criterion

Schwarz criterion
4.62E-07

$4.45 \mathrm{E}-08$

100.9679

$-4.913994$

$-2.852399$

Recebido em 20.01.16 Aprovado em 10.10.16 
